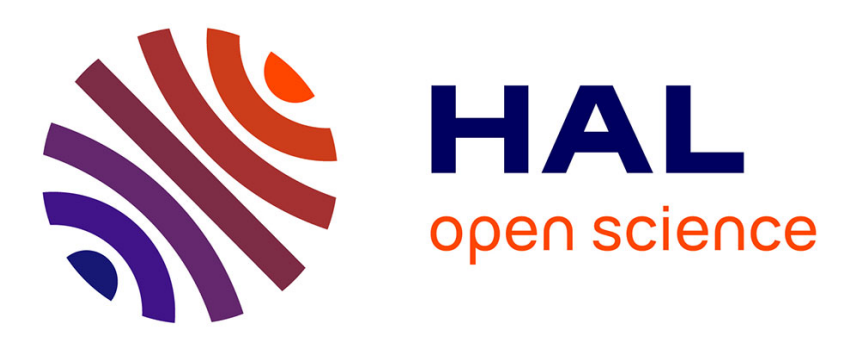

\title{
A direct method for the solution of evolution problems
} François Comte, M. Maitournam, Pierre Burry, T. Mac Lan Nguyen

\section{To cite this version:}

François Comte, M. Maitournam, Pierre Burry, T. Mac Lan Nguyen. A direct method for the solution of evolution problems. Comptes Rendus Mécanique, 2006, 334 (5), pp.317-322. 10.1016/j.crme.2006.02.007 . hal-00111464

\section{HAL Id: hal-00111464 https://hal.science/hal-00111464}

Submitted on 8 Dec 2018

HAL is a multi-disciplinary open access archive for the deposit and dissemination of scientific research documents, whether they are published or not. The documents may come from teaching and research institutions in France or abroad, or from public or private research centers.
L'archive ouverte pluridisciplinaire HAL, est destinée au dépôt et à la diffusion de documents scientifiques de niveau recherche, publiés ou non, émanant des établissements d'enseignement et de recherche français ou étrangers, des laboratoires publics ou privés. 


\title{
A direct method for the solution of evolution problems
}

\author{
François Comte $^{\mathrm{a}, \mathrm{b}, \mathrm{c}, *}$, Habibou Maitournam ${ }^{\mathrm{a}}$, Pierre Burry ${ }^{\mathrm{b}}$, T. Mac Lan Nguyen ${ }^{\mathrm{b}}$ \\ a Solid Mechanics Laboratory, CNRS UMR 7649, Department of Mechanics, École polytechnique, 91128 Palaiseau cedex, France \\ b PSA Peugeot Citroën, Division of automotive research and innovation, route de Gisy, 78943 Vélizy Villacoublay, France \\ c UME, ENSTA, chemin de la Hunière, 91761 Palaiseau, France
}

\begin{abstract}
An alternative numerical method to solve structural evolution problems is presented. It belongs to the family of Large Time Increment Methods. The problem is solved on the whole time interval separating a global stage where a SA and KA solution is searched and a local stage where the constitutive law is satisfied. To solve the global stage, consuming the most CPU time, the mechanical fields are decomposed in a wavelet basis and the equilibrium is solved only for the largest coefficients.
\end{abstract}

\section{Résumé}

La méthode directe. Cette Note présente une méthode numérique alternative de résolution de problèmes transitoires. Elle s'inscrit dans le cadre des méthodes à Grand Incrément de Temps; la solution est recherchée sur la totalité du trajet de chargement en résolvant alternativement un problème dit global où l'on recherche une solution SA et CA et un problème local où on satisfait la loi de comportement. L'étape globale étant la plus coûteuse en temps de calcul, sa résolution se fait en décomposant le chargement sur une base d'ondelettes et en résolvant l'équilibre uniquement pour les coefficients d'ondelettes les plus importants.

Keywords: Computational solid mechanics; Solids and structures; Large increment; Wavelets

Mots-clés : Mécanique des solides numérique; Solides et structures ; Grand incrément ; Ondelettes

\section{Version française abrégée}

Le travail présenté porte sur un nouvel algorithme de résolution numérique développé dans le cadre de la simulation d'un procédé de traitement thermique pour les culasses en aluminium. La prise en compte du process, et par conséquent la détermination de l'état mécanique résiduel, est importante pour prédire la tenue en service de la culasse.

\footnotetext{
* Corresponding author.

E-mail addresses: comte@1ms.polytechnique.fr, francois.comte1@mpsa.com (F. Comte), habibou@lms.polytechnique.fr (H. Maitournam), pierre.burry@mpsa.com (P. Burry), maclan.nguyen@mpsa.com (T. Mac Lan Nguyen).
} 
Cependant une telle simulation effectuée de manière incrémentale nécessite aujourd'hui des durées trop importantes pour les bureaux d'études. Un nouvel algorithme permettant de réduire les temps de calcul pour obtenir l'état mécanique résiduel de la structure est nécessaire.

L'approche proposée repose sur la méthode à grand incrément de temps développée par P. Ladevèze [1] et la méthode cyclique directe développée par H. Maitournam et al. [2]. De la première méthode on retient l'idée d'un traitement du problème transitoire non plus d'une manière incrémentale mais directement sur la totalité de l'intervalle de temps. Les équations y sont séparées en équations globales (on parle de problème global) linéaires et équations locales (on parle de problème local) éventuellement non linéaires. Les deux types d'équations sont résolus alternativement jusqu'à convergence, convergence qui se trouve alors améliorée. De la seconde méthode, utilisée pour déterminer directement l'état asymptotique d'une structure sous chargement cyclique, on retient l'idée de projection des différents champs thermomécaniques sur une base de fonctions adaptée afin de réduire le coût de l'étape globale.

Ces principes sont utilisés ici pour la recherche, non pas de l'état stabilisé sous chargement cyclique, mais de la solution d'un problème transitoire sous chargement variable sur une durée donnée.

Lors de la résolution de l'étape globale deux points principaux guident le choix de la base de projection :

- la projection d'un signal sur la base orthonormée de l'espace fonctionnel doit permettre de représenter correctement ce signal avec un nombre raisonnable de coefficients;

- le support des fonctions de base doit être de taille finie ou du moins, celles-ci doivent décroître rapidement vers zéro en dehors d'un intervalle de taille finie.

Le premier point est primordial pour diminuer le temps nécessaire à la résolution de l'étape globale. Le second est important pour pouvoir affiner l'évolution des grandeurs mécaniques sur seulement une partie de l'intervalle d'étude $[0, T]$ où cela s'avèrera nécessaire.

Le choix de la base de décomposition s'est porté sur les ondelettes. En effet un signal décomposé sur une base d'ondelettes peut être représenté par son approximation à une échelle grossière complétée des détails aux échelles intermédiaires [5]. Aux échelles les plus fines, qui servent à décrire ce qui se passe de manière locale, les coefficients d'ondelettes seront de faible valeur pour un signal ne subissant pas de variations rapides; seuls seront donc à prendre en compte les coefficients correspondant à des zones proches des points singuliers.

En partant de l'équation d'équilibre, un schéma de type Newton permet d'obtenir l'Éq. (4) portant sur les coefficients d'ondelettes. Ce système, symétrique, de grande taille, avec un certain nombre de matrices élémentaires nulles peut être résolu avec des méthodes telles que MINRES [6]. Lorsqu'un modèle de type Newton modifié est utilisé, ce système se simplifie sous la forme de l'Éq. (5); les équations sont alors découplées pour tous les coefficients d'ondelettes.

L'étape locale est classiquement réalisée par projection sur le convexe d'élasticité avec l'algorithme de retour radial $[3,4]$.

Afin de tester la méthode, l'algorithme a été implémenté sous Matlab. On traite ici le cas d'une plaque trouée élastoplastique avec des caractéristiques mécaniques dépendant de la température, soumise à un chargement thermomécanique. Une bonne adéquation des résultats entre la méthode directe et la méthode incrémentale est observée.

\section{Introduction}

Nowadays, numerical modeling is mandatory in process development and validation of automotive components. Because of the large number of degrees of freedom of the F.E. models (about one million for a cylinder head), the complex loading and the nonlinear constitutive laws, calculation time is often prohibitive. In that case, computations cannot been used in an optimisation process.

The purpose of this Note is to propose a new numerical method to reduce calculation time. This method is based on the Large Time Increment Method and the wavelet decomposition for the equilibrium solution.

\section{Problem position}

Let us consider the quasi-static evolution, on a time interval $[0, T]$, of a structure made from a non-linear material. From its initial state, the structure is subjected at each time $t$ to volumic body force $f(x, t)$ on its volume $\Omega$ 
and to surface forces $\boldsymbol{T}^{\boldsymbol{d}}$ on $\partial \Omega_{T}$, part of the structure surface $\partial \Omega$. On surface $\partial \Omega_{u}$, complementary to $\partial \Omega_{T}$, displacements $\boldsymbol{u}(\boldsymbol{x}, t)$ are imposed. A temperature field $T(\boldsymbol{x}, t)$, result of a previous thermal calculation, is also given. The evolution satisfies the hypothesis of infinitesimal transformations. For simplicity, the material is assumed to be thermoelastoplastic.

The solution of the problem, defined on $[0, T] \times \Omega$, consists of the displacements $\boldsymbol{u}$, strains $\boldsymbol{\varepsilon}$, plastic strains $\boldsymbol{\varepsilon}^{\boldsymbol{p}}$ and stresses $\sigma$, whose evolutions are obtained on $[0, T] \times \Omega . \sigma$ is statically admissible (SA), $\boldsymbol{u}$ kinematically admissible (KA) and $\varepsilon, \varepsilon^{p}$ and $\sigma$ are related through the constitutive equations (PA).

\section{Principle of the solution algorithm}

From a general point of view, the approach is based on two main methods: the Large Time Increment Method developed by Ladevèze [1] and the Direct Cyclic Method by Maitournam et al. [2]. From the first one, we retain the fact that the problem is directly treated on the whole time interval by separating a linear global stage where a statically and kinematically admissible (SKA) response is looked for and a local stage where a plastically admissible (PA) solution is obtained. This solution scheme accelerates the solution convergence. The second suggests that in the global stage, consuming the most CPU time, the loading is decomposed in a specific basis. In this method, suitable for cyclic loadings, since a periodic limit response of the structure is sought, Fourier decomposition is used. For the general evolution problem, where the solution is not periodic, the Fourier expansion is not appropriate and a better projection has to be found.

The iterative process can then be broken down into:

- a global stage: on the whole interval [0,T], a SKA solution is searched. The problem, written in its discretized residual form $K \Delta u(t)=R^{\mathrm{eq}}(t)$, is solved after a projection on a suitable basis. The choice of this basis is mainly motivated by two points. Firstly, the residual forces must be precisely represented with only a short number of coefficients. This point is very important because the shorter the number of kept coefficients is, the shorter the computational time for each global stage is. However, the solution must be correctly represented and a minimum number of coefficients is necessary. Secondly, the basis function support should be, if it is possible, compact. This point enables the correction of the solution only on parts of the interval where the residue is important.

- a local stage: from the solution obtained at the global stage, a PA solution is determined on the whole path. An incremental calculation in the time domain, done at all the instants $t_{k}$, projects the SKA solution onto the elastic convex using the return mapping algorithm $[3,4]$.

- a residue discounting: once the solution $\sigma^{\mathrm{PA}}$ carried out, the residue is computed.

The algorithm initiation is classically determined by solving the purely elastic problem. The convergence criterion refers to the plastic admissibility condition of the SKA solution determined during the global stage.

\section{Wavelet analysis of a signal}

Wavelet analysis [5] is based on the decomposition of a signal $s$ into an approximation sub-space and details subspaces at different scales. From an iterative point of view, from the sub-space $V_{j}$, approximation $V_{j+1}$ and details $W_{j+1}$ are built. Mother wavelet $\varphi$, that has a null mean value, is used to define the details and, at the opposite, the scaling function $\psi$ enables to calculate the approximations. In several cases both functions are reals and have compact supports. At the different scales, the functions $\psi_{j, n}(t)=2^{-j / 2} \psi\left(2^{-j} t-n\right)$ and $\varphi_{j, n}(t)=2^{-j / 2} \varphi\left(2^{-j} t-\right.$ $n)$ with $j, n \in \mathbb{Z}$ are used to calculate the wavelet and scaling coefficients:

$$
\left\{\begin{array}{l}
a_{j}^{n}=\left\langle s, \varphi_{j, n}\right\rangle=\frac{1}{\sqrt{2}} \int_{-\infty}^{+\infty} s(t) \bar{\varphi}\left(2^{-j} t-n\right) \\
d_{j}^{n}=\left\langle s, \psi_{j, n}\right\rangle=\frac{1}{\sqrt{2}} \int_{-\infty}^{+\infty} s(t) \bar{\psi}\left(2^{-j} t-n\right)
\end{array}\right.
$$


$2^{-j}$ is the scaling factor of the wavelet, and $n$ is the translation, and so localisation, parameter. Therefore $a_{j}^{n}$ and $d_{j}^{n}$ describe the behavior of $s$ around the instant $2^{-j} n$.

The signal can therefore be decomposed into an approximation at a coarse level $j_{0}$, completed by details at all the intermediate ones:

$$
s(t)=\sum_{i=j_{0}}^{j-1} \sum_{k} d_{k}^{i} \psi_{i k}(t)+\sum_{k} a_{k}^{j_{0}} \varphi_{j_{0} k}(t)
$$

Scaling and wavelet coefficients, at the low levels, describe the function globally. On the other hand, at the fine levels, a local description is carried out. Thus, at those scales, wavelet coefficients are small when the signal is smooth, and the detail coefficients are significant only in discontinuous areas. An efficient approximation can be carried out keeping only the important ones.

For a fixed number $N$ of coefficients, the approximation error will be minimized considering only the $N$ basis functions $\psi_{j, n}$ and $\varphi_{j, n}$ for which the absolute values of coefficients $a_{j}^{n}$ or $d_{j}^{n}$ are the largest.

Therefore, from the exact relation (2), the following approximation (3) is obtained.

$$
s(t) \simeq \sum_{i=j_{0}}^{j-1} \sum_{k^{\prime} \in\left[1, m_{i}\right]} d_{k^{\prime}}^{i} \psi_{i k^{\prime}}(t)+\sum_{k^{\prime} \in[1, l]} a_{k^{\prime}}^{j_{0}} \varphi_{j 0} k^{\prime}(t) \quad \text { with } N=l+\sum_{i} m_{i}<N_{\text {instants }}
$$

In the following, without distinguishing wavelet and scaling functions, the notation will be

$$
s(t) \simeq \sum_{i=1}^{N} \alpha_{i} q_{i}(t) \quad\left(\text { or } \sum_{i=1}^{N} \beta_{i} q_{i}(t)\right)
$$

\section{New resolution of the global stage}

The residue decomposition $R^{\mathrm{eq}}(t)$ on a wavelet basis enables to represent its evolution with only a few coefficients. Moreover, because the support length and the localisation of the basis functions are variable, the correction of the solution can be carried out only on one part of the studied interval $[0, T]$. In that case, on the other part where the obtained solution has already converged, no basis function, and so no correction, is necessary.

From $K(t) \Delta u(t)=R^{\mathrm{eq}}(t)$, decomposing $\Delta u(t)$ and $R^{\mathrm{eq}}(t)$ into their basis functions, the equation

$$
\sum_{j=1}^{N} K(t) \alpha_{j}(M) q_{j}(t)=\sum_{j=1}^{N} \beta_{j}(M) q_{j}(t)
$$

is obtained and, multiplying by the test function $q_{i}(t)$ leads to

$$
\sum_{j=1}^{N} K(t) \alpha_{j}(M) q_{i}(t) q_{j}(t)=\sum_{j=1}^{N} \beta_{j}(M) q_{i}(t) q_{j}(t) .
$$

By integrating over the whole interval $[0, T]$ we obtain

$$
\sum_{j=1}^{N}\left[\int_{0}^{T} K(t) q_{i}(t) q_{j}(t) \mathrm{d} t\right] \alpha_{j}(M)=\sum_{j=1}^{N}\left[\int_{0}^{T} q_{i}(t) q_{j}(t) \mathrm{d} t\right] \beta_{j}(M)
$$

that can be rewritten

$$
\tilde{K} \tilde{\alpha}(M)=\tilde{\beta}(M)
$$

where

$$
\widetilde{K}_{i j}=\int_{\operatorname{Supp} q_{i}(t) \cap \operatorname{Supp} q_{j}(t)} K(t) q_{i}(t) q_{j}(t) \mathrm{d} t, \quad \tilde{\alpha}=\left[\begin{array}{c}
\alpha_{1}(M) \\
\vdots \\
\alpha_{N}(M)
\end{array}\right] \quad \text { and } \quad \tilde{\beta}=\left[\begin{array}{c}
\beta_{1}(M) \\
\vdots \\
\beta_{N}(M)
\end{array}\right]
$$


In general, the size of this system is important because the size of the matrix $[\widetilde{K}]$ is $N \times N_{\text {dof }}$ over $N \times N_{\text {dof }}$. However, in most cases, $[\widetilde{K}]$ presents an important number of elementary matrices $\left[\widetilde{K}_{i j}\right]$ equal to zero. One reason is linked to the multi-scale approach in the wavelet decomposition. Because of the compact length of the wavelet basis functions, $q_{i}(t)$ and $q_{j}(t)$ supports can be disjoined. In this case, the intersection of the supports being empty, $\left[\widetilde{K}_{i j}\right]$ equals zero. Otherwise the $\left\{q_{k}(t)\right\}_{k \in\{1, N\}}$ basis is, in most cases, orthonormal. So, if $K(t)$ is constant over $\operatorname{Supp} q_{i}(t) \cap \operatorname{Supp} q_{j}(t)$ then $\left[\widetilde{K}_{i j}\right]=K \delta_{i j}$. Thus, if $i \neq j$, the relation $\left[\widetilde{K}_{i j}\right]=[0]$ is still satisfied. Another important fact to reduce the calculation time is that $\left[\widetilde{K}_{i j}\right]$ is a real symmetric matrix. Some interesting solution methods can therefore be applied to systems of considerable size to solve the global stage such as MINRES [6].

When plastic strains are small or when the tangent modulus is quite important compared to the Young's modulus, a modified Newton method may be a good alternative to the method previously presented. The stiffness matrix is considered constant and equal to its initial value. In that particular case $\left[\widetilde{K}_{i j}\right]=K \delta_{i j}$ and

$$
[\tilde{K}]=\left[\begin{array}{llll}
K & & & \\
& K & & \\
& & \ddots & \\
0 & & & K
\end{array}\right]
$$

Only the diagonal blocs remain and, for each wavelet coefficient, the system becomes

$$
K \alpha_{i}=\beta_{i} \quad \forall i \in\{1 ; N\}
$$

\section{Numerical results}

In order to illustrate the method, the case of a holed plate submitted to a thermomechanical loading is treated. The constitutive law is von Mises elastoplastic with a linear kinematic hardening depending on the temperature (Fig. 1(a)). Because of the problem symmetry, only a quarter of the plate has been meshed and adequate boundary conditions have been applied (Fig. 1(b)).

A first uncoupled thermal computation enables the determination of the temperature field $T(x, t)$ in the whole structure. In the mechanical calculation, carried out with Matlab, a traction is applied on the surface in $x=L / 2$ in the $y$-axis direction and a thermal gradient is present in the thickness. In Fig. 2, similar levels of plastic strains on the contours of the plate at the instant $t=T$ can be observed for the incremental method and the direct method. The calculation result, presented on the $[0, T]$ interval, at the most loaded point (the surrounded point on Fig. 1(b)), shows again a good agreement between the two methods. A superposition of the two curves after convergence is shown in Fig. 1(c). Moreover, compared to an incremental simulation, the calculation time is reduced.

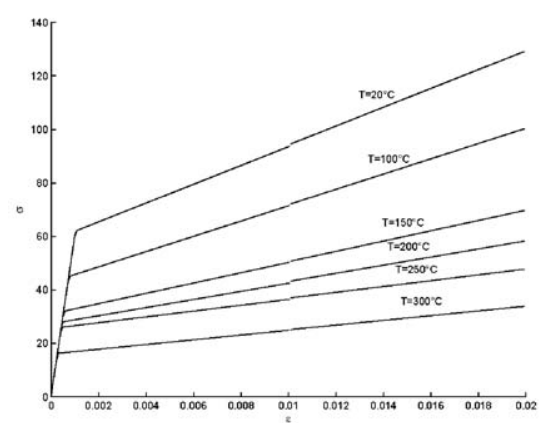

(a) Constitutive law depending on the temperature

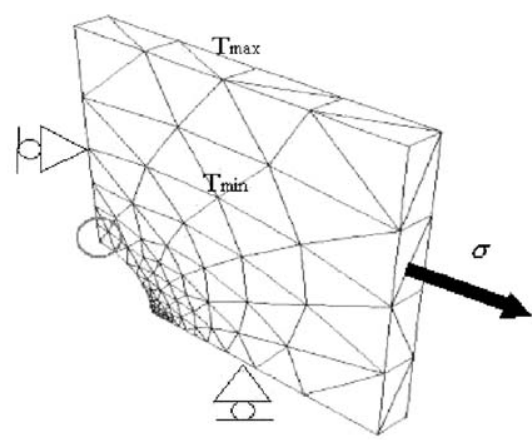

(b) Mesh of the holed plate

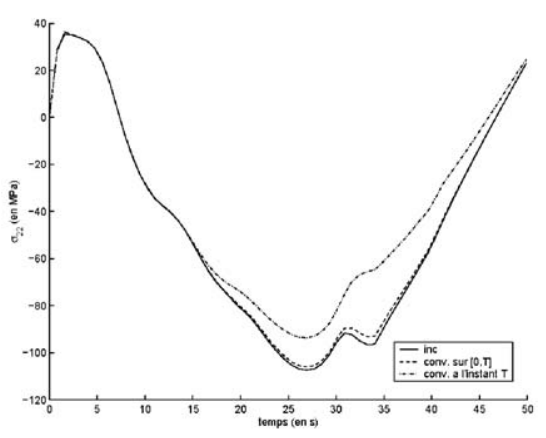

(c) Comparison of the numerical results

Fig. 1. Calculation of a holed plate submitted to a thermomechanical loading.

Fig. 1. Calcul d'une plaque trouée soumise à un chargement thermomécanique. 

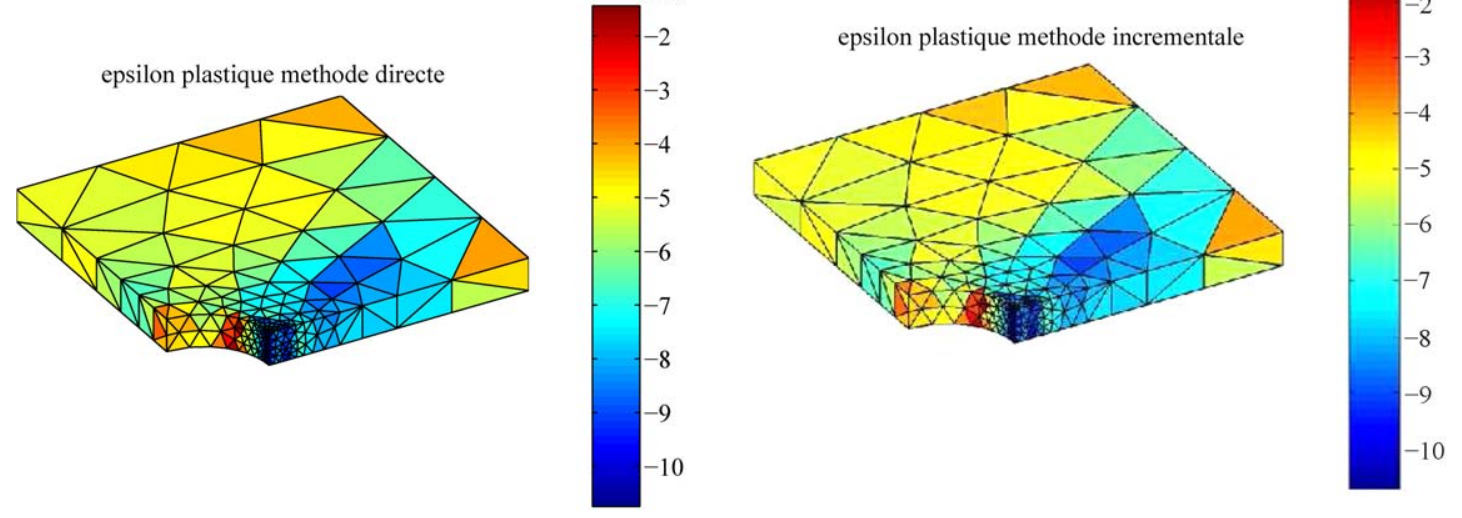

Fig. 2. Residual plastic strains with the direct (left) and the incremental method (right).

Fig. 2. Déformations plastiques résiduelles avec les méthodes directe (gauche) et incrémentale (droite).

\section{Conclusion}

The direct method presented in this paper enables the determination of the solution $\left(\boldsymbol{u}, \boldsymbol{\varepsilon}, \boldsymbol{\varepsilon}^{p}\right.$ and $\left.\boldsymbol{\sigma}\right)$ of structural evolution problems over the entire time interval of interest. It belongs to the class of large time increment methods and uses the wavelet transform. During the global stage, because of the wavelet adaptability, such a basis is used to expand the different fields. Hence the different signals can be well represented, even in complex cases, with a few coefficients. The example presented shows a good agreement between the incremental method and the direct method.

\section{References}

[1] P. Ladevèze, Nonlinear Computational Structural Methods: New Approaches and Non Incremental Methods of Calculation, Springer-Verlag, Berlin/New York, 1998.

[2] H. Maitournam, B. Pommier, J.J. Thomas, Détermination de la réponse asymptotique d'une structure anélastique sous chargement thermomécanique cyclique, C. R. Mecanique 330 (2002) 703-708.

[3] Q.S. Nguyen, On the elastic plastic initial-boundary value problem and its numerical integration, Int. J. Numer. Methods Engrg. 11 (1977) 817-832.

[4] J.C. Simo, R.L. Taylor, Consistent tangent operators for rate-independent elastoplasticity, Comput. Methods Appl. Mech. Engrg. 48 (1985) $101-118$.

[5] S. Mallat, A Wavelet Tour of Signal Processing, Academic Press, San Diego, CA, 1999.

[6] A. Greenbaum, Iterative Methods for Solving Linear Systems, SIAM, Philadelphia, 1997. 